\title{
Testing Thermal Properties of Cooling Device with Heat Pipes to Improve His Heat Transfer Ability
}

\author{
Patrik Nemec, Alexander Čaja and Milan Malcho \\ Department of Power Engineering, Faculty of Mechanical Engineering, University of Žilina, Žilina 01026, Slovakia
}

Received: June 05, 2013 / Accepted: September 04, 2013 / Published: February 28, 2014.

\begin{abstract}
This paper deals about testing thermal properties of the cooling device with heat pipes at inclination position, in consequence of using the natural convection to improve heat transfer properties. Head point testing of cooling device is monitoring temperature on the aluminium block of energy converter, heat pipes and ribs under temperature condition $30{ }^{\circ} \mathrm{C}$ in thermostatic chamber. Testing of the device was performed at tilt angles positions 0,10 and $20^{\circ}$ from the vertical level. The heat flux loaded to energy converter was $450 \mathrm{~W}$. The next goal of the paper is to research on influence working position of the wick heat pipe on their thermal performance. In this research heat pipes were made with capillary structure sintered from copper powder granularity 100,63 and $50 \mu \mathrm{m}$ filled with water and ethanol. Next heat pipe thermal performance was performed by measuring heat source and working positions. Knowledge of these two research goals can bring potential improvements in purpose of cooling device for effective heat sink from high power electronic components.
\end{abstract}

Key words: Heat pipe, heat transfer, cooling device.

\section{Introduction}

It is expected that heat flux levels in excess of 100 $\mathrm{W} / \mathrm{cm}^{2}$ for commercial electronics will soon become a realistic and immediate challenge to overcome. There is also a growing demand for more sophisticated and capable electronics used in harsh environment applications such as those found in defence, automotive and oil exploration systems. Thermal management of harsh environment electronics is vital to the successful design, manufacture, and tactical operation of a variety of electronics systems to meet the high temperature, environment, reliability, and cost effectiveness requirements [1]. Capillary-driven two-phase systems offer significant advantages over traditional single phase systems and heat transfer systems by transferring thermal conductivity. With the typically increased thermal capacity associated with the phase change of a working fluid, considerably

Corresponding author: Patrik Nemec, Ph.D., research field: heat transfer systems. E-mail: patrik.nemec@fstroj.uniza.sk. smaller mass flow rates are required to transport equivalent amounts than those in other heat transfer systems for a given temperature range. Moreover, heat transfer coefficients of two-phase systems are much greater than other systems and result in enhanced heat transfer. Lower mass flow rates and enhanced thermal characteristics provide the benefits of smaller system size (and weight) while providing increased performance. The thermal capacity of a single-phase system depends on the temperature change of the working fluid; thus, a large temperature gradient or a high mass flow rate is required to transfer a large amount of heat. However, a two-phase system can provide essentially isothermal operation regardless of variations in the heat load. Additionally, single phase systems require the use of mechanical pumps and fans to circulate the working fluid, while capillary-driven two-phase systems have no external power requirements, which make such systems more reliable and free of vibration. Heat pipes are passive devices that transport heat from a heat source (evaporator) to a 
heat sink (condenser) over relatively long distances via the latent heat of vaporization of a working fluid [2]. The concept of the heat pipe was first presented by Gaugler et al. [3, 4], but was not widely publicized until an independent development by Grover [5] at the Los Alamos Scientific Laboratories. To predict the operation limitations of heat pipes, Chi [6] and Peterson [7] both have mentioned theories about limits. Peterson and $\mathrm{Ha}[8]$ have developed both experimental tests and analytical models to predict the dry-out point for evaporating liquid in triangular microgrooves. Then, Cao and Gao [9] have carried out experimental investigations on the thermal performance of flat miniature heat pipes. Mughal and Plumb [10] investigated boiling on a wicked surface. Wang et al. [11-13] investigated two-phase flow and phase change in porous media using computational fluid dynamics and lattice Boltzmann methods. Cerza and Boughey [14] predicted the capillary limit of heated and inclination triangular capillary grooves. However, it is still difficult to apply these theoretical approaches to the practical heat pipes. From the time when heat pipe patented was used in practice, heat transfer of phase change of working fluid systems is more and more widely used. And whereby further more industrial branches try to compose the heat pipe into its heat transfer process or operation of thermal devices in order to cool them or stabilize temperature. The most widespread branch of heat pipe applications is still electrical engineering, where the heat pipes are used for cooling power switches. This situation makes researcher in the area of heat pipe research and development do test of various kinds and types of configurations heat pipes for these applications.

\section{Testing Thermal Properties of the Cooling Device}

The cooling device consists of energy converter and cooler. The energy converter consists of electronic components which during operation produce heat. Produced heat influent operation and lifetime of the energy converter therefore needs waste heat removed to the surrounding. The cooler of the energy converter is constructed from six gravitational pipes filled with ethyl alcohol. Their evaporation section is embedded into the aluminium block of the energy converter and on the condensation section are ribs connected vertically to the axis of the heat pipes. Usually this energy converter is installed in the control unit of the rail vehicle. Great impact on heat sink has ambient conditions and if the vehicle is moving or does not move. If the vehicle is moving the heat transfer from energy converter to surrounding, it is caused by forced convection of air flow around device. But if the vehicle does not move critical situations will move, when no air flows the condenser of the cooler and heat sink is not as intensive as in the case if the air flows around the device. At this time, if ambient temperature is high, overheating of the energy converter can occur. Therefore it is important to find cooling performance of the cooling device under high temperature condition. Fig. 1 shows the thermostatic chamber. The chamber must have a sufficient capacity for creating conditions for heat transfer by natural convection to simulate the adjustable and continuously stationary temperatures around cooling device. The chamber has volume $1 \mathrm{~m}^{3}$ and is coated by polystyrene with a thickness $10 \mathrm{~cm}$. Inside the chamber is mounted pipeline connected to the thermostat. Heating medium circulates in pipes from the thermostat and heats the interior of the chamber. More details of the construction and measurement in thermostatic chamber are described [15]. Head point testing of cooling device in thermostatic chamber is monitoring temperature on the aluminium block of energy converter, heat pipes and ribs under temperature condition $30{ }^{\circ} \mathrm{C}$ and various positions of device. The energy converter was loaded with constant heat flux $450 \mathrm{~W}$.

Temperature measurement of the device was set at different tilt angles of about 0,10 and $20^{\circ}$ from the vertical level. Intention of the measurement was to 

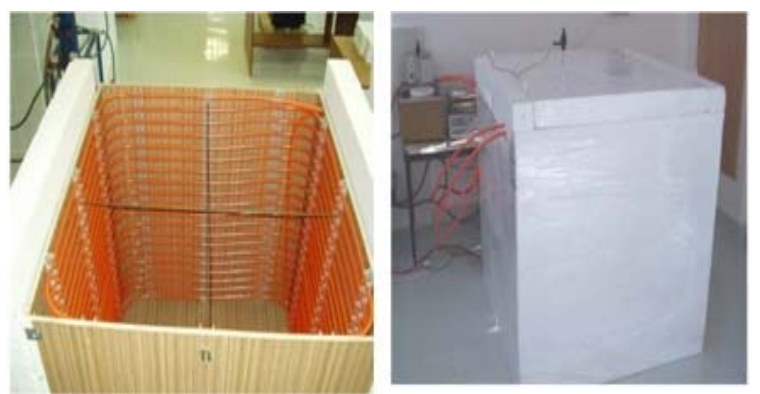

Fig. 1 Thermostatic chamber for cooling device testing.

ascertain dependence of the heat transferred upon tilt angle of the cooling device with gravitational heat pipes from the vertical level. Therefore for determination efficiency of the cooling device from the working position, thermocouples scanned surface temperature course of the each heat pipes, the fins of the cooler, the alumina block and the energy converter. All the temperature data were recorded into a computer by a measurement central. Figs. 2-4 show results from testing thermal properties of cooling device at various positions and at surrounding temperature $30^{\circ} \mathrm{C}$. In all, the three positions were observed highest temperature on the energy converter of the device. Fig. 5 shows temperature course comparison of energy converter depending on position.

In vertical line the highest temperature was measured $142{ }^{\circ} \mathrm{C}$, at the first tilt angle $10^{\circ}$ from vertical position was the highest temperature measured $136{ }^{\circ} \mathrm{C}$ and at the second tilt angle $20^{\circ}$ from vertical position the highest temperature was measured $132{ }^{\circ} \mathrm{C}$. During temperature measurement of cooling device temperature was observed on the electric converter drop between vertical position and position at inclination $20^{\circ}$ from vertical position approximately $10{ }^{\circ} \mathrm{C}$. Result of the test is that, the increasing of the tilt angle of the cooling device is possible to increase its ability to heat transfer but only up to a certain point. After exceeding the critical point, heat transfer ability of the cooling device starts decreasing. Therefore, if the fin cooler is tilted, the fins are tilted in a certain angle from the vertical level too and in that way the heat transfer by natural convection increases too. Increasing the tilt angle is possible only up to the point when the

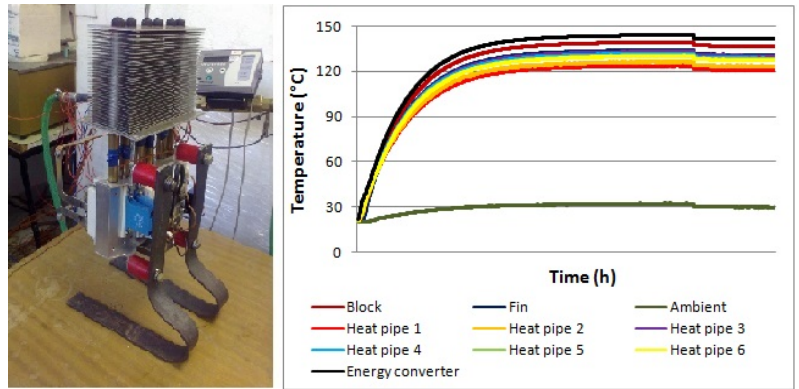

Fig. 2 Graphic results from the temperature measurement of the cooling device at vertical position.
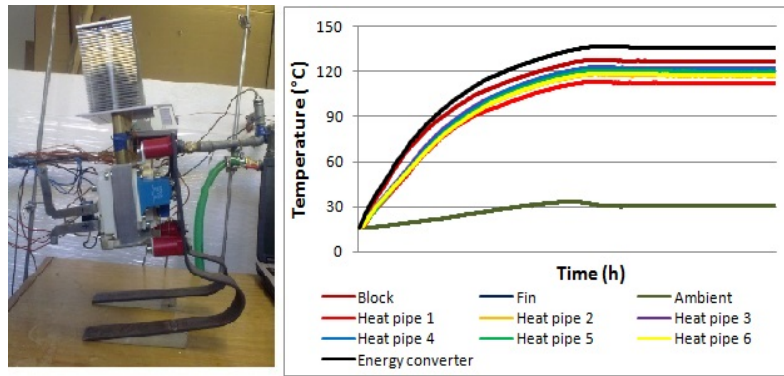

Fig. 3 Graphic results from the temperature measurement of the cooling device at tilt angle $10^{\circ}$ position.
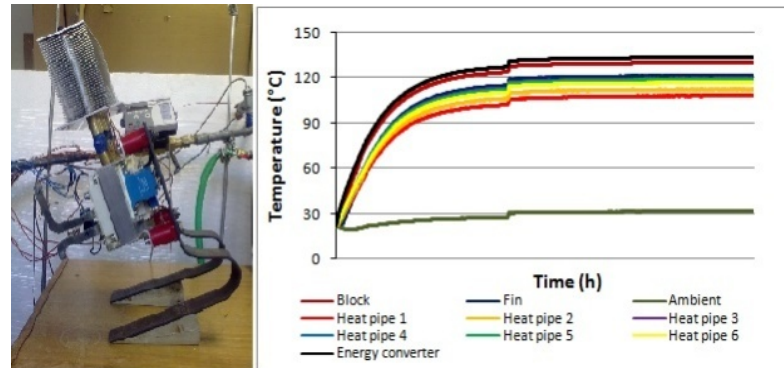

Fig. 4 Graphic results from the temperature measurement of the cooling device at tilt angle $20^{\circ}$.

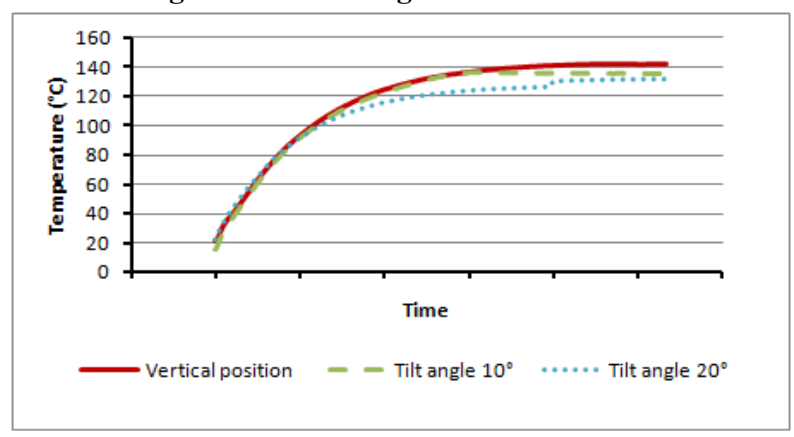

Fig. 5 Temperature course of the cooling device at various positions.

condensate in heat pipes is still able to return from condensation section to the evaporation section. At a higher tilt angle of the fin cooler heat removal is more intensively by natural convection but the return of the condensate to the evaporator section fails and that is the 
reason why its overall ability of the heat transfer decreases. The option how to improve heat transfer by natural convection to the surrounding is application of the wick heat pipe because the wick heat pipe is able to operate at tilt angle $45^{\circ}$ position without any problems. This claim confirms study about influence working position of wick heat pipe on their performance [16-18].

\section{Heat Transfer by Wick Heat Pipes}

The major components of a heat pipe are a sealed container, a wick structure and a working fluid. The wick structure is placed on the inner surface of the heat pipe wall and is saturated with the liquid working and provides the structure to develop the capillary action for liquid returning from the condenser to the evaporator. Return of the liquid to the evaporator from the condenser is provided by wick structure.

\subsection{Heat Pipe Container}

The container, working fluid, and wick structure of a heat pipe determine its operational characteristics. One of the most important considerations in choosing the material for the heat pipe container and wick is its compatibility with the working fluid. Degradation of the container or wick and contamination of the working fluid due to chemical reaction can seriously impair heat pipe performance. For example, non-condensable gas created during a chemical reaction eventually can accumulate near the end of the condenser, decreasing the condensation surface area. This reduces the ability of the heat pipe to transfer heat to the external heat sink. The material and geometry of the heat pipe container also must have a high burst strength, low weight, high thermal conductivity, and low porosity [19].

\subsection{Working Fluid}

Using the proper working fluid for a given application is another critical element of proper heat pipe operation. The working fluid must have good thermal stability properties at the specified operational temperature and pressure. The operational temperature range of the working fluid has to lie between its triple point and its critical point for liquid to exist in the wicking material. The wetting ability of the working fluid contributes to its capillary pumping and priming capability. High-surface-tension fluids are commonly used in heat pipes because they provide the capillary pumping and wetting characteristics necessary for proper operation. Other desirable thermo physical properties include a high liquid thermal conductivity, high latent heat of vaporization, low liquid viscosity and a low vapor viscosity [19].

\subsection{Wick Structures}

The wick provides a means for the flow of liquid from the condenser to the evaporator section of the heat pipe. It also provides surface pores that are required at the liquid-vapor interface for development of the required capillary pressure. The wick structure also has an impact on the radial temperature drop at the evaporator end between the inner heat pipe surface and the liquid-vapor surface. Thus, an effective wick requires large internal pores in a direction normal to the heat flow path. This will minimize liquid flow resistance. In addition, small surface pores are required for the development of high capillary pressure and a highly conductive heat flow path for minimization of the radial surface to liquid-vapor surface temperature drop. For liquid transport in heat pipe developed, several types of wick structure and the cross sections are shown in Fig. 6. One common wick structure is the wrapped screen wick shown in Fig. 6a. This type of wick structure is designated by its mesh number, which is an indication of the number of pores per unit length or unit surface area. The surface pore size is inversely proportional to the mesh number and the liquid flow resistance can be controlled by the tightness of the wrapping. This is attractive, but because of the interruptions in the wick metal by a liquid of low thermal conductivity in the moderate-range heat pipe, the radial temperature drop from the inner pipe surface 


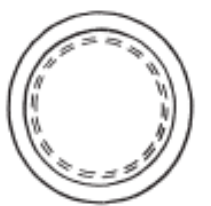

(a) Wrapped screen

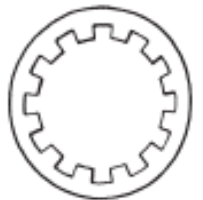

(c) Axial groove

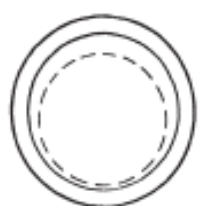

(e) Crescent

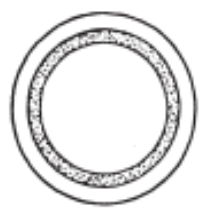

(b) Sintered metal

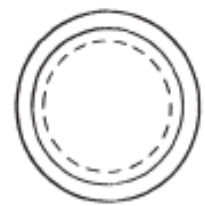

(d) Annular

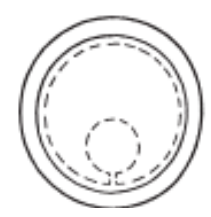

(f) Artery
Fig. 6 Cross sections of the wick structures [6].

to the liquid-vapor surface at the evaporator end can be quite high. This problem can be alleviated through use of the sintered metal wick structure shown in Fig. $6 \mathrm{~b}$. Notice here that the pore size is small but the small pores will make it more difficult for the liquid to flow from the condenser to the evaporator. The axially grooved wick shown in Fig. 6c possesses highly conductive metal paths for the minimization of radial temperature drop. Axially grooved heat pipes are most commonly found in space applications. The annular and crescent wicks, shown respectively in Figs. $6 \mathrm{~d}$ and 6e, have small resistance to liquid flow but are vulnerable to liquids of low thermal conductivity. The artery wick, shown in Fig. $6 \mathrm{f}$ was developed to reduce the thickness of the radial heat flow path through the structure and to provide a low-resistance path for the liquid flow from the condenser to the evaporator. However, these wicks often lead to operating problems if they are not self-priming, because the arteries must fill automatically at startup or after dryout [2]. As an alternative application for heat transfer, improvement of cooling device was manufactured and tested on our workplace department copper heat pipes with sintered capillary structure.
This experiment was made three various capillary structures by sintering from copper powders with granularity of 100, 63 and $50 \mu \mathrm{m}$ applying the copper powder to the inner wall of the copper pipe (in Fig. 7). Capillary structure of heat pipes from cooper powder was sintered in the high thermal electric oven using for powder metallurgy. With this method a $1.5 \mathrm{~mm}$ thick coat of sintered capillary structure was created. The overall length of the heat pipes is $0.45 \mathrm{~m}$. The choices of the capillary system for the wick heat pipes depend on many factors and only a few of these factors are related to the properties of the working fluid. The working fluid must have good thermal stability in relation to the specific working temperature and pressure. The most important requirements which the working fluid must have are the following: compatibility with the capillary system and with the material of the pipe, high thermal stability, high state of heat, high thermal conductivity, low viscosity of the liquid and vapour phase, high surface tension and acceptable freezing point. Therefore water and ethanol were chosen as a working fluid. Amount of working fluid in heat pipes is $20 \%$ from overall heat pipe volume as discussed [20]. Working fluid was injected into the pipe via connecting capillary by syringe. Pipe with working fluid was connected to vacuum pump and inner air from pipe was sucking off. Before connecting pipe, vacuum system had to cool working fluid by immersing pipe in to the cooling medium, because during vacuuming of the pipe pressure drop occurs and this may cause evaporation of working fluid. After vacuuming was connecting capillary cramping, cutting from vacuum system and ending of heat pipe were soldering.

\subsection{Measurement of Heat Pipe Thermal Performance}

Heat pipe is simple but ingenious device to heat transfer. Heat transfer through heat pipe occurs when based on evaporation and consequential condensation of working fluid. By this means it is possible to transfer great thermal performance by little dimension devices, 
too. One of many methods of how to determine performance of heat pipe is calorimetric method. Calorimetric method emanates from calorimetric equation with respect to known mass flow, specific heat capacity, input and output temperature of coolant. Total heat power of heat pipe determines from difference between input and output temperature of circumfluent coolant. The experimental measurement has proposed measuring unit, which consists of measuring apparatus (thermostat, measuring centre and ultrasonic flow meter, auto-transformer (in Fig. 8)). It was necessary to measure thermal performance of heat pipe. Heat source for the heat pipe was controllable transformer, which was connected with resistance wire to heat pipe. Temperature of heat pipe evaporator section was measuring with $\mathrm{NiCr}-\mathrm{Ni}$ thermocouple taped on heat pipe surface. Electrical isolation under resistance wire constituted mica tape. Evaporator section of heat pipe was heating by resistance wire connecting on the transformer, which regulates necessary working temperature of heat pipe. To determine heat pipe performance was designed and cooling system consisted of small copper pipe placed on condenser section of heat pipe.
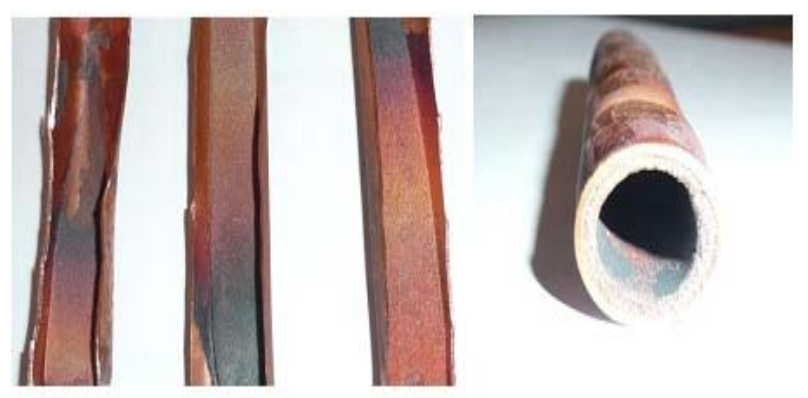

Fig. 7 Wick heat pipe with sintered capillary structure.

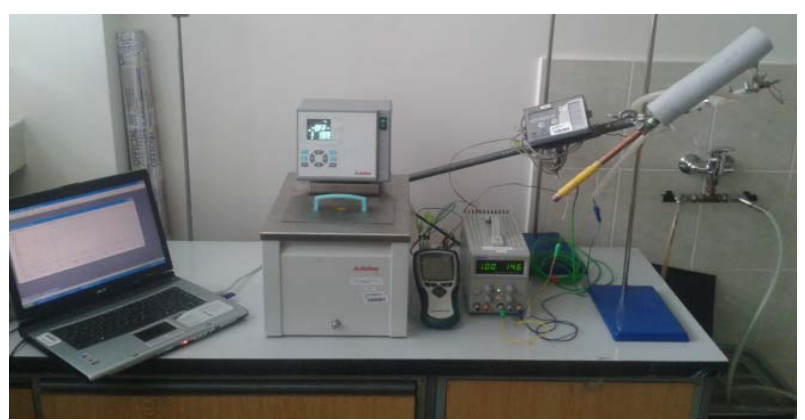

Fig. 8 Experimental measurement of heat pipe performance.
Surface of heat pipe was painted with heat-conductive paste to make it better to transfer heat from heat pipe to cooling system. After the cooling system flows cooling water, it is regulated by thermostat. The input and output temperature flowing water through cooling system is measured by $\mathrm{NiCr}-\mathrm{Ni}$ thermocouples. Adiabatic and condensate section of heat pie is isolated by polystyrene as a heat loss protection into surround. The temperature and mass flow data from measuring enter into measuring centre and from software AMR to PC. Heat performance transferred from evaporator to condensate section by heat pipe is calculated on the basis of calorimetrical equation from measured value of input and output temperature, mass flow and special thermal capacities cooling water circulate in cooling system [21]. Measurement of thermal performance of heat pipes was at vertical and tilt angle $45^{\circ}$ position and temperature of heat source $50^{\circ} \mathrm{C}$ and $70^{\circ} \mathrm{C}$. Heat performance solution of heat pipe is based on calorimetrical equation and values from experimental measuring.

$$
\begin{aligned}
& \bar{Q}=\dot{m} c_{p} \Delta \overline{t_{l}} \\
& \Delta \overline{t_{l}}=\overline{t_{0}}-\overline{t_{p}}
\end{aligned}
$$

where, $\Delta \bar{t}_{l} \quad\left({ }^{\circ} \mathrm{C}\right)$-temperature difference, $\overline{t_{p}}$ $\left({ }^{\circ} \mathrm{C}\right)$-input temperature, $\overline{t_{0}}\left({ }^{\circ} \mathrm{C}\right)$ - output temperature, $\dot{m}\left(\mathrm{~J} \cdot \mathrm{kg}^{-1} \cdot \mathrm{K}^{-1}\right)$ - mass flow of liquid, $c_{p}$ $\left(\mathrm{J} \cdot \mathrm{kg} \cdot \mathrm{s}^{-1}\right)$ - special thermal capacities of liquid.

Fig. 9 shows results from experimental measuring heat performance of wick heat pipe with sintered capillary structure from copper powder $63 \mu \mathrm{m}$ granulate at vertical position. Figs. 10 and 11 show investigated values of wick heat pipes thermal performance on position at heat source temperature $50{ }^{\circ} \mathrm{C}$ and $70{ }^{\circ} \mathrm{C}$. Fig. 12 shows percentage difference of wick heat pipes thermal performance at tilt angle $45^{\circ}$ against vertical position. It is seen that the average value of thermal performance of all kinds sintered wick heat pipes at tilt angle $45^{\circ}$ position is just about $11 \%$ less than at vertical position.

The founding of the present experiment can help to improve heat transfer ability of the cooling device. The future work will be dealt with substitution gravity 


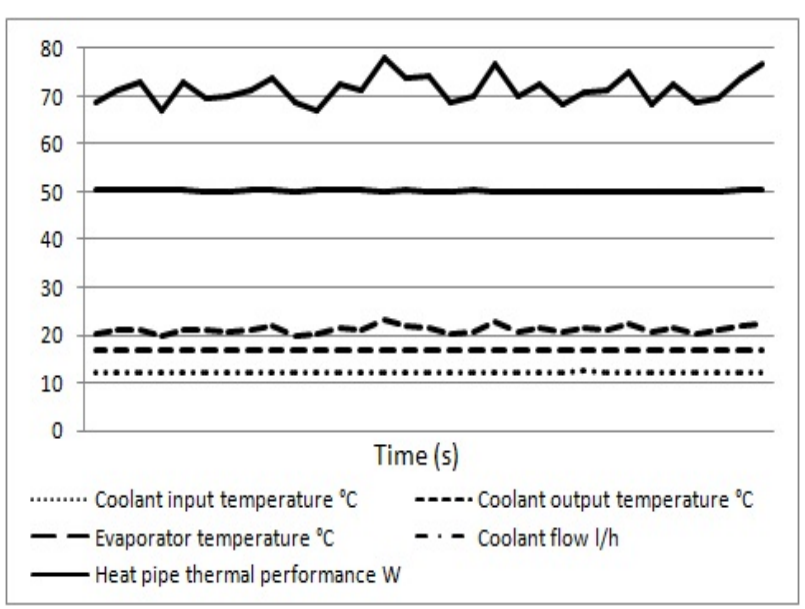

Fig. 9 Results of the experimental measuring heat performance of wick heat pipe with sintered capillary structure from copper powder $100 \mu \mathrm{m}$ granulate at tilt angle position.

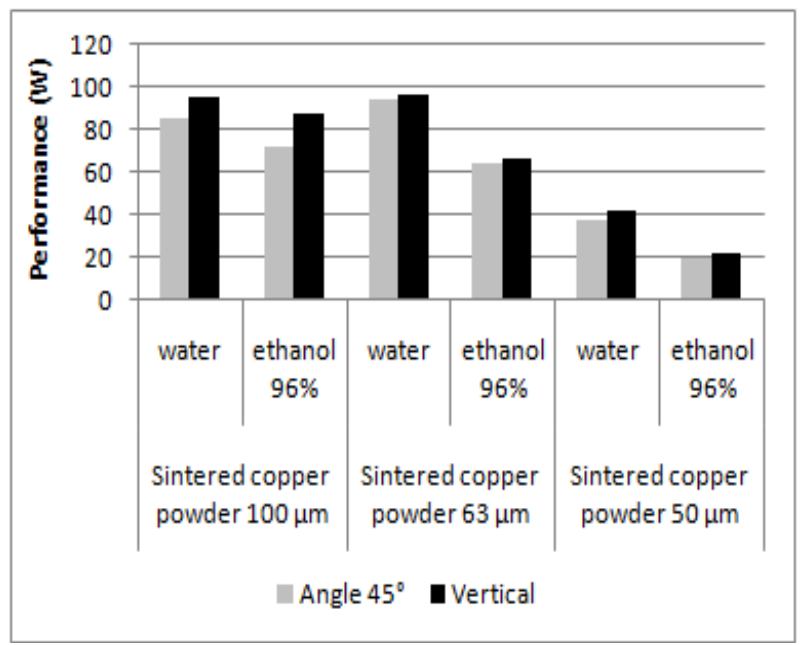

Fig. 10 Dependencies of wick heat pipes thermal performance on position at heat source temperature $50{ }^{\circ} \mathrm{C}$.

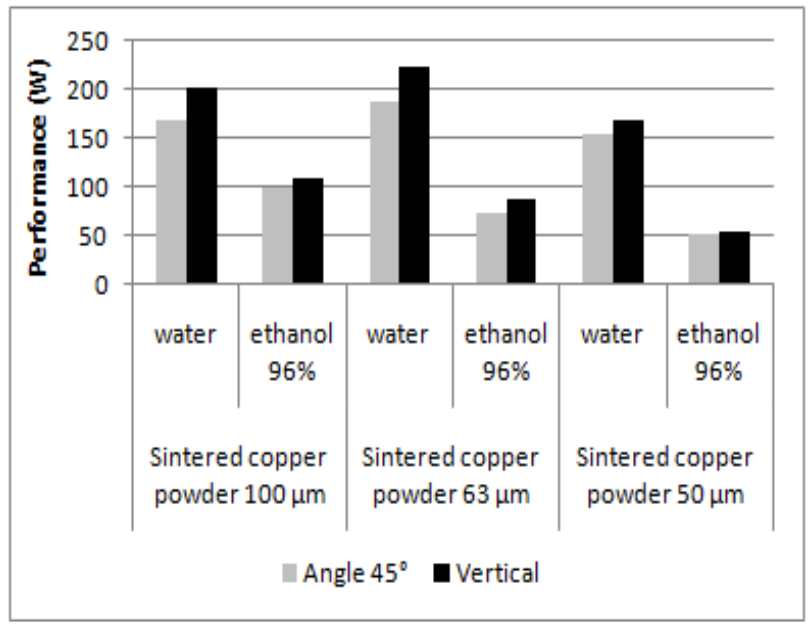

Fig. 11 Dependencies of wick heat pipes thermal performance on position at heat source temperature $70^{\circ} \mathrm{C}$.

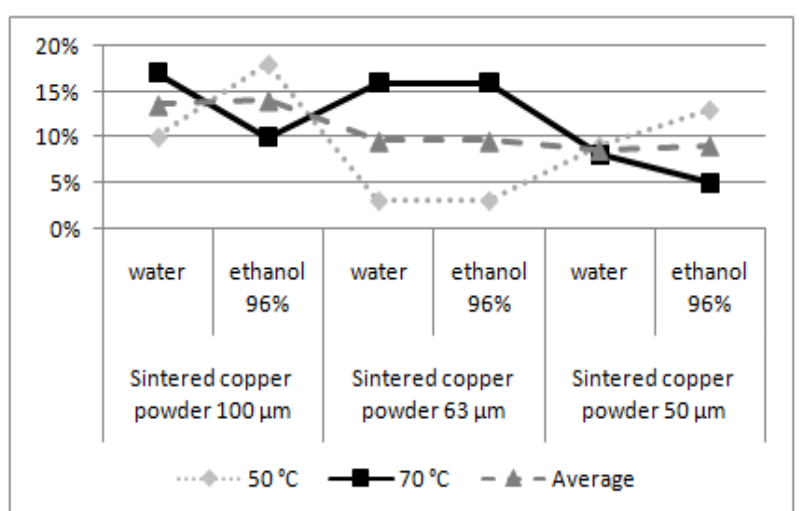

Fig. 12 Percentage difference of wick heat pipes thermal performance at tilt angle $45^{\circ}$ against vertical position at heat source temperature $50^{\circ} \mathrm{C}$ and $70{ }^{\circ} \mathrm{C}$.

which assists heat pipes instead of wick heat pipes and will be performed measurements influence of position on heat transfer of the cooling device with wick heat pipes and future results will be compared with present results.

\section{Conclusions}

Experiment brings two conclusions. The first conclusion is positive influence of fin cooler inclination on heat transfer, resulting in temperature drop of energy converter about $10{ }^{\circ} \mathrm{C}$ between vertical position and tilt angle $20^{\circ}$ position. The second conclusion is minimal influence inclination of wick heat pipe on transferred thermal performance, resulting in thermal performance drop about $11 \%$ between vertical position and tilt angle $45^{\circ}$ position. Therefore, the tilt of fin cooler and substitution of wick heat pipes instead gravitation heat pipes will improve heat transfer by natural convection of fin cooler to the surrounding, whereby the thermal performance transferred from heat source by wick heat pipes will be approximately the same.

\section{Acknowledgments}

This article was created within the frame of project APVV-0448-07.

\section{References}

[1] M. Ohadi, J. Qi, Thermal management of harsh 
environment electronics, Microscale Heat Transfer, Fundamentals and Applications, NATO Science Series, II Mathematics, Physics and Chemistry, Springer (formerly Kluwer Academic Publishers), 2005, pp. 479-498.

[2] J.M. Ochterbeck, Heat pipes, Heat Transfer Handbook, in: A. Bejan, A. Kraus (Eds.), John Wiley and Sons Inc., USA, 2003.

[3] R.S. Gaugler, Heat transfer devices, US Patent, 2350348 (1944).

[4] L. Trefethen, On the surface tension pumping of liquids or a possible role of the candlewick in space exploration, GE Tech. Int. Ser. No. G15-D114, General Electric Co., NY, 1962.

[5] G.M. Grover, T.P. Cotter, G.F. Erikson, Structures of very high thermal conductivity, J. Appl. Phys. 218 (1964) 1190-1191.

[6] S.W. Chi, Heat Pipe Theory and Practice: A Sourcebook, Hemisphere Publishing Corp., Washington, 1976, pp. $33-86$.

[7] G.P. Peterson, Heat Pipes-Modelling, Testing and Applications, John Wiley \& Sons Inc., New York, 1994, pp. 44-99.

[8] G.P. Peterson, J.M. Ha, Capillary performance of evaporating flow in micro grooves: An approximate analytical approach and experimental investigation, J. Heat Transfer 120 (1998) 743-751.

[9] Y. Cao, M. Gao, Experiments and analyses of flat miniature heat pipes, in: Proceedings of the $31 \mathrm{st}$ Intersociety Energy Conversion Engineering Conference, Washington DC, USA, 1996.

[10] M.P. Mughal, O.A. Plumb, An experimental study of boiling on a wicked surface, Int. J. Heat Mass Trans. 39 (4) (1996) 771-777.

[11] J.Y. Wang, N. Christakis, M.K. Patel, M.C. Leaper, M.A. Cross, Numerical model of coupled heat and moisture transfer with phase change in granular material during varying environmental conditions, Numer Heat Trans, Part
A 45 (8) (2004) 751-776.

[12] J.Y. Wang, X.X. Zhang, A.G. Bengough, J.W. Crawford, Parallel lattice Boltzmann simulation of incompressible flows in porous media, Phys. Rev. 72 (016706) (2005) 1-11.

[13] J.Y. Wang, X.X. Zhang, A.G. Bengough, J.W. Crawford, Performance evaluation of cell-based algorithms for domain decomposition in flow simulation, Int. J Numer Meth Heat Fluid Flow 18 (5) (2008) 657-671.

[14] M. Cerza, B. Boughey, The effects of air infiltration on a large flat heat pipe at horizontal and vertical orientations, ASME J Heat Trans. 125 (3) (2003) 49-55.

[15] A. Kapjor, A. Kosecová, Š. Papučík, Influence of construction parameters to heat output of floor convector, in: Proceedings of the TRANSCOM, 6th European Conference of Young Research and Science Workers in Transport and Telecommunications, 2005, pp. 69-72.

[16] S.D. Garner, Heat pipes for electronics cooling applications, Electronics Cooling 12 (3) (1996).

[17] G. Huminic, A. Huminic, I. Morjan, F. Dumitrache, Experimental study of the thermal performance of thermosyphon heat pipe using iron oxide nanoparticles, International Journal of Heat and Mass Transfer 54 (1-3) (2011) 656-661.

[18] R. Manimaran, K. Palaniradja, N. Alagumurthi, J. Hussain, Factors affecting the thermal performance of heat pipe-A review, JERS 3 (2) (2012) 20-24.

[19] L.W. Swanson, Heat pipe, Heat and mass transfer, mechanical engineering handbook, in: F. Kreith (Ed.), CRC Press LLC, Boca Raton, 1999.

[20] R. Lenhard, Numerical simulation device for the transport of geothermal heat with forced circulation of media, in: Proceedings of the Power Control and Optimization, Kuching, Malaysia, 2010.

[21] J. Jandačka, R. Nosek, Š. Papučík, Analysis factors influencing emission and performance parameters of the small heat sources, in: Proceedings of the Vykurovanie (Heating), Bratislava, Slovakia, 2011, pp. 95-98. 